\title{
Perceived Job Insecurity and Anxiety. A Multilevel Analysis on Male and Female Workers in European Countries
}

\author{
Anna Bracci ${ }^{1 *}$ and Egidio Riva ${ }^{2}$ \\ ${ }^{1}$ Department of Business Economics, Health and Social Care, University of Applied Sciences and Arts of Southern \\ Switzerland, Manno, Switzerland, ${ }^{2}$ Department of Sociology and Social Research, University of Milano-Bicocca, Milan, Italy
}

\section{OPEN ACCESS}

Edited by:

Christiana lerodiakonou, University of Cyprus, Cyprus

Reviewed by:

loulia Bessa,

Leeds University Business School,

United Kingdom Anna Carreri,

University of Trento, Italy

*Correspondence: Anna Bracci anna.bracci@supsi.ch

Specialty section:

This article was submitted to Work, Employment and Organizations, a section of the journal Frontiers in Sociology

Received: 17 June 2020

Accepted: 26 August 2020

Published: 17 September 2020

Citation:

Bracci A and Riva E (2020) Perceived Job Insecurity and Anxiety. A Multilevel Analysis on Male and Female Workers in European Countries.

Front. Sociol. 5:573549.

doi: 10.3389/fsoc.2020.573549
A growing body of evidence has been produced on the adverse effects of job insecurity on health and well-being. Current research in the field conveys a few concerns, some of which are related to gender and cross-national differences in the experience of job insecurity. In order to fill these gaps this study draws on three waves (2005, 2010, 2015) of the European Working Conditions Survey and investigates, using mixed-effects logistic regression: (i) the relationship between anxiety and perceived job insecurity; and whether such relationship: (ii) is different for men and women; (iii) and varies across European countries. Results indicate that male and female workers perceiving the risk of involuntary job loss have similar odds of reporting anxiety. Furthermore, the variance in slopes across countries, relative to the general trend, is significant but modest, too, thus suggesting that the relationship under investigation is fairly similar across European countries. Implications of the findings for future research and practice are discussed.

Keywords: anxiety, job insecurity, European countries, multilevel analysis, gender differences

\section{INTRODUCTION}

Over the last few years a combination of factors, such as globalization, the widespread digitalization, labor market deregulation and the prevalence of employment in service industries over manufacturing - has made new forms of work organization more pervasive (Greenan et al., 2017). In particular, different types of non-standard or atypical employment (namely fixed-term, temporary or casual contracts) have increased and have lowered employment stability and overall social protection (Sengenberger, 2011; De Stefano, 2016). Workers in permanent contracts have also been exposed to these phenomena, which have resulted in a substantial lessening of restrictions on dismissal, as well as organizational downsizing, merges and acquisitions (OECD, 2014). Accordingly, the overall number of workers experiencing job insecurity, which is generally defined as the perceived threat of job loss and job discontinuity (De Witte et al., 2016), has widely enlarged.

A growing body of literature has proved a negative association between perceived job insecurity, on the one hand, and health or subjective well-being, effective functioning at work, and occupational outcomes, on the other hand (for meta-analyses and literature reviews, see e.g., Sverke et al., 2002; Cheng and Chan, 2008; Berkman et al., 2014; De Witte et al., 2016). Accordingly, the issue of job insecurity has been relatively high on the policy-making agenda and it has gained increasing attention in a wide range of disciplines. Nonetheless, current research in the field conveys a few concerns, some of which are related to gender and cross-national differences in the experience of job insecurity (László et al., 2010). 
The constant and rapid growth in female employment rates has surely expanded the opportunities women may benefit from; however, it is widely demonstrated that female workers tend to have less favorable work and employment conditions compared to their male counterparts (Felstead et al., 2015; Grimshaw et al., 2017). In particular, although several studies indicate that women usually report better working time quality and face fewer physical hazards, there is evidence of severe and persistent gender inequalities in careers patterns and contractual arrangements (Fagan and Burchell, 2002; Olsen et al., 2010; Green and Mostafa, 2012; Eurofound, 2017a). Indeed, across the world, women are highly concentrated in specific sectors and occupations and are overrepresented in temporary or non-standard employment (ILO, 2016), partly as a result of the greater difficulties they face in entering and remaining into the labor market due to the unequal distribution of time allocated to unpaid work. That said, findings on gender-specific consequences of precarious jobs on health and well-being are not conclusive. Some studies found that the strength of the association between precariousness and health is fairly similar among men and women (Pelfrene et al., 2003; Green, 2011; Reichert and Tauchmann, 2017; Kachi et al., 2018; Menéndez-Espina et al., 2019). Other research suggested that responses to adverse work and employment conditions may be different for men and women (Kalil et al., 2010; Cottini, 2012). Finally, a number of studies indicate that the link between job insecurity and health among female workers is negligible (Wang et al., 2008; Watson and Osberg, 2017).

Furthermore, to the best of our knowledge, there is little published data on cross-national differences in the relationship between the fear of involuntary job loss and health or wellbeing. Economic and political variables (such as labor market regulation, employment protection legislation, welfare policies, unemployment rate) as well as prevailing cultural frameworks could predict diversity in health-related outcomes of the experience of job insecurity (Erlinghagen, 2008; László et al., 2010; Balz, 2017). Nonetheless, most research in the field has so far investigated single countries, such as UK (Ferrie et al., 2005), Germany (Reichert and Tauchmann, 2017), Spain (MenéndezEspina et al., 2019), Finland (Griep et al., 2016), Denmark (Cottini and Ghinetti, 2018), the United States (Simmons and Swanberg, 2008), Japan (Kachi et al., 2018), Australia (Green, 2011), and Canada (Wang et al., 2008). Even the studies of Buffel et al. (2015) and Caroli and Godard (2016), whose analyses drew on large and international datasets, have not provide crosscountry comparative analyses. Hence, there is abundant room to advance the understanding of how perceived job insecurity may differently impact the well-being and health of (female) workers in different countries.

In order to contribute filling these gaps, this study draws on the European Working Conditions Survey (EWCS) (Eurofound, 2017b) - which is a nationally representative dataset of employees and the self-employed in European countriesand investigates, using multilevel modeling: (i) the association between perceived job insecurity and a self-reported measure of anxiety from a gender perspective; (ii) whether such relationship varies across countries. The topic is quite important for policy purposes, given that labor market change, along with welfare retrenchment, has produced new social risks (Bonoli, 2005), which have mainly affected women (OECD, 2017). In addition, psychological well-being is crucial for both employers and national governments, as long as it has a wide range of direct and indirect social and economic costs (OECD, 2012). For instance, in the public health framework, policymakers should pay specific attention to women employed in insecure jobs, since women are more exposed to the medicalization of social problems and more likely to use medical treatment as a common coping mechanism (Buffel et al., 2015).

The remainder of this paper is structured as follows. The next section begins by laying out the theoretical background and literature review. Section Data and Methods is concerned with the data and the methodology used for this study. The fourth section presents the findings. Section Results discusses the results, while the final section discusses some implications for policy-making and future research.

\section{LITERATURE REVIEW AND RESEARCH PROPOSITIONS}

Previous research indicates that perceived job insecurity is a stressor, which is therefore positively correlated to poorer mental well-being, in general, and anxiety, in particular (Simmons and Swanberg, 2008; Burgard et al., 2009; Milner et al., 2016; Cottini and Ghinetti, 2018; Wood and Burchell, 2018). For instance, Simmons and Swanberg (2008) found that job insecurity is the single most significant correlate of depressive symptoms for working poor employees. Some findings also prove that the fear of involuntary job loss is comparable to unemployment in affecting mental health (Green, 2011; Griep et al., 2016; Reichert and Tauchmann, 2017).

The most authoritative frameworks on the health and behavioral consequences of job insecurity, such as work stress theories, highlight that social or psychological variables act as key determinants or moderator variables (Sverke et al., 2002; De Witte et al., 2016). The perceived risk of involuntary job loss is expected to have adverse effects due to a stressful work environment, which does not provide enough rewards in return for the high efforts (as in the effort-reward imbalance model, see Siegrist and Wahrendorf, 2016), or due to a lack of control that workers may have over their jobs (as in the job demandcontrol model, see Karasek, 1979). More in general, experiences, such as the anticipation of frustration at work, unpredictability and uncontrollability, the consumption of available resources (Janlert and Hammarström, 2009), which are all associated to the prolonged uncertainty inherent in job insecurity, may lead to reduced mental health and well-being.

Job insecurity may produce health-related negative outcomes as a consequence of gender-specific employment patterns and exposure to different work and employment conditions. We mainly refer to the fact that female workers, compared to their male counterparts, tend to be segregated into passive or lowcontrol jobs, which are associated with poorer health status (O'Campo et al., 2004; Cottini, 2012), or report lower overall job quality (Simões et al., 2015). Furthermore, on average, 
women still fulfill the large majority of unpaid work obligations. Hence employment, especially when insecure, may have adverse effects on health also because of possible work-family conflicts (Menéndez et al., 2007; Wang et al., 2008; Avendano and Berkman, 2014). In this respect, literature highlights that a variety of coping strategies and social support may buffer the detrimental consequences that the experience of job insecurity could have on job attitudes and health among women (see e.g., Kalil et al., 2010; Menéndez-Espina et al., 2019). Hence, based on previous literature, we may anticipate the following hypothesis:

\section{H1: Perceived job insecurity predicts anxiety, in both the female and male subsamples}

Turning to cross-country differences, distinct reactions to precariousness may arise from peculiar country-level variables and characteristics. In countries where breadwinner norms are still predominant, the association between job insecurity and health may be comparatively lower for women compared to men, as these are expected to contribute the most to the household income. In addition, the non-economic gender approach, which attributes inequalities to patriarchy and gender stereotypes within institutions and interactional contexts, could explain the low or negligible effects of insecurity as a stressor among women (Wang et al., 2008; Cloutier et al., 2009; Stier and Yaish, 2014). On the other hand, within a more gender-egalitarian culture, the negative effects of perceived job insecurity may be significant for women as much as for men (Kachi et al., 2018). Within this general framework, the results of the study conducted by László et al. (2010), one of the few that have adopted a cross-country perspective, are quite interesting. Using cross-sectional data, the authors have analyzed the association between job insecurity and health among working people aged 45-70 years in 16 European countries and have obtained similar results in both male and female subsamples. In more detail, this study shows that job insecurity is significantly associated with an increased risk of poor health in countries, such as Czech Republic, Denmark, Germany, Greece, Hungary, Israel, the Netherlands, Poland, and Russia; conversely, small or no relationships are found in Austria, France, Italy, Spain and Switzerland, Belgium and Sweden. It is quite evident that the grouping of countries does not seem to follow any of the existing models in the welfare regimes or varieties of capitalism literature (e.g., Esping-Andersen, 1990; Hall and Soskice, 2001) or in cross-cultural studies (e.g., Hofstede, 1991). Based on these findings we may reason that:

H2: Male and female workers perceiving the risk of involuntary job loss have similar odds of reporting anxiety

H3: The relationship between job insecurity and anxiety varies across countries.

\section{DATA AND METHODS}

\section{Sample}

This study employs three waves $(2005,2010,2015)$ of the European Working Conditions Survey (EWCS) (Eurofound, $2017 b)$. Due to the geographical coverage of the survey in all
TABLE 1 | Summary statistics, by gender.

\begin{tabular}{|c|c|c|c|c|}
\hline & \multicolumn{2}{|c|}{ Men } & \multicolumn{2}{|c|}{ Women } \\
\hline & $N$. & Freq. (\%) & $N$. & Freq. (\%) \\
\hline \multicolumn{5}{|l|}{ AGE } \\
\hline $15 / 34$ & 13,474 & 29.7 & 12,266 & 27.7 \\
\hline $35 / 44$ & 11,795 & 26.0 & 11,889 & 26.9 \\
\hline $45+$ & 20,174 & 44.4 & 20,093 & 45.4 \\
\hline \multicolumn{5}{|l|}{ EDUCATION } \\
\hline Primary & 3,399 & 7.7 & 2,264 & 5.2 \\
\hline Secondary & 29,147 & 65.7 & 26,055 & 60.2 \\
\hline Tertiary & 11,800 & 26.6 & 14,982 & 34.6 \\
\hline \multicolumn{5}{|c|}{ EMPLOYMENT STATUS } \\
\hline Employee & 35,608 & 79.5 & 38,235 & 88.1 \\
\hline Self-employed & 9,197 & 20.5 & 5,187 & 11.9 \\
\hline \multicolumn{5}{|l|}{ SECTOR } \\
\hline Private & 33,647 & 79.6 & 26,566 & 65.6 \\
\hline Public & 8,642 & 20.4 & 13,921 & 34.4 \\
\hline \multicolumn{5}{|l|}{ WORK-LIFE FIT } \\
\hline Very well & 12,146 & 26.8 & 13,945 & 31.6 \\
\hline Well & 23,113 & 51.1 & 22,408 & 50.7 \\
\hline Not very well & 7,605 & 16.8 & 6,321 & 14.3 \\
\hline Not at all well & 2,410 & 53.2 & 1,516 & 34.3 \\
\hline \multicolumn{5}{|c|}{ JOB SATISFACTION } \\
\hline Not at all satisfied & 1,834 & 4.1 & 1,470 & 37.0 \\
\hline Not very satisfied & 6,846 & 15.1 & 6,571 & 15.0 \\
\hline Satisfied & 26,307 & 58.1 & 25,506 & 58.0 \\
\hline Very satisfied & 10,285 & 22.7 & 10,512 & 23.3 \\
\hline \multicolumn{5}{|c|}{ PRIMARY EARNER IN THE HOUSEHOLD } \\
\hline No & 8,629 & 19.0 & 23,447 & 53.2 \\
\hline Yes & 36,704 & 81.0 & 20,648 & 46.8 \\
\hline
\end{tabular}

three waves, the original sample was initially restricted to 30 European countries (the $28 \mathrm{EU}$ member states plus Norway and Turkey) and subsequently further reduced to include only those who answered the question assessing the dependent variable $(N=90,048)$. Both male $(N=45,621)$ and female $(N=44,427)$ and male workers were predominantly aged $15-44$ years $(55.6$ and $54.6 \%$, respectively) and well-educated: $26.6 \%$ of sampled men and $34.6 \%$ of their female counterparts have achieved tertiary qualifications. The large majority of men (79.5\%) are employees and work in the private sector $(79.6 \%)$, mainly in manufacturing $(18.3 \%)$, other services $(14.0 \%)$, wholesale and retail trade (13.8\%), and construction activities (12.3\%). Sampled women are comparatively more present in the public sector (35.4\%) and predominantly work in other services (40.3\%), wholesale or retail trade $(16.0 \%)$, and manufacturing (11.2\%). Finally, it is worth mentioning that $46.8 \%$ of female workers are the person who contributes the most to the household income. For comprehensive descriptive statistics, see Table 1.

\section{Variables}

A self-reported indicator of anxiety ("Over the last 12 months, did you have any of the following health problems? Anxiety"), 
dummy coded, was selected as the outcome variable of this study. The main predictor (i.e., perceived job insecurity) was measured through this question: "To what extent do you agree or disagree with following statement about your job: I might lose my job in the next 6 months." Based on Chung (2018), the original response categories were dichotomized. In more detail, those who answered "strongly agree" or "tend to agree" were considered as perceiving the risk of involuntary job loss, whereas those who answered "neither agree or disagree," "tend to disagree," and "strongly disagree" were considered as those who did not feel their job insecure. Based on previous studies (Watson and Osberg, 2017; Kachi et al., 2018), a wide range of control variables were included in the model. Firstly, we added individual variables: age, recoded in three categories (15-34; 35-44; 45-54 years); educational attainment (primary, secondary, and tertiary level); employment status (employee vs. self-employed); sector (public vs. private) the respondent worked in; perceived work-life fit, ranging from $1=$ very well to $4=$ not very well; job satisfaction, ranging from $1=$ very satisfied to $4=$ not at all satisfied. In line with Caroli and Godard (2016), this latter variable was added to control for working conditions and psychosocial work environment; indeed, omitting an evaluation of working conditions could lead to an upward bias in estimations. Year of the survey and whether the respondent was the person who contributed the most to the household income were inserted as control, too. All observations with a missing value in any of the variables in the model were excluded from the analyses.

\section{Methods}

In dealing with hierarchically structured data, we estimated a mixed-effects logistic regression model in which observations at level 1 (i.e., individuals) were nested within European countries (level 2). The model was designed with a random intercept and a random slope for perceived job insecurity in order to test whether the relationship under scrutiny might vary across countries. The variance-covariance structure of these two random effects was treated as unstructured. To make the interpretation of the regression model more meaningful, the estimated coefficients were displayed as odds ratios. Separate regression models were run for male and female subsamples.

\section{RESULTS}

\section{Descriptive Statistics}

The observed proportion reporting anxiety across European countries is $17.8 \%$ among working women and $13.4 \%$ among working men. In Germany, Austria, Denmark, Romania, and Slovakia $<10 \%$ of sampled individuals suffer from this specific health problem; on the other hand, in Estonia, Greece, and Cyprus over a third of both male and female workers report this mental problem. On average, about a quarter $(24.7 \%)$ of female respondents who feel their job is insecure suffer from anxiety, whereas only $16.4 \%$ of those who do not perceive the risk of involuntary job loss are anxious. As for working men, about a fifth (18.8\%) of those perceiving their job as insecure report anxiety; on the contrary, $12.4 \%$ of those who have secure jobs struggle with anxiety. As Figure 1 shows, the gap in the proportion of female workers reporting anxiety between those who perceive their job as insecure and those who do not is comparatively higher in countries, such as Austria (about 18\% points), Luxembourg (about 16\% points), Bulgaria (about 14\% points) and lower in most Mediterranean countries (e.g., Malta, Italy, Portugal, and Spain) as well as in several continental European countries (e.g., Germany, Slovenia, and Belgium). In the male subsample such gap is relatively bigger in Cyprus (14\% points), UK ( $12.6 \%$ points), and Norway (12.5\% points) and smaller in countries, such as Ireland, Spain, Slovenia, Austria, and Lithuania.

\section{Mixed-Effect Logistic Regression}

Results of multilevel analysis for working women are displayed in Table 2. The empty or null model (Model 1), which has no explanatory variables and allows intercepts to vary across countries, provides the decomposition of the variance of the dependent variable. The intraclass correlation coefficient is equal to 0.0855 , which means that about $8.55 \%$ of the variance in the probability to report anxiety is attributable to the contextual level (i.e., level 2). Thus, a multilevel model is appropriate.

In Model 2 (random intercept and fixed slope model) explanatory variables at level 1 were added. Coefficients indicate that female workers who feel their job is insecure are significantly more likely to report anxiety. In particular, if a working woman reports job insecurity, her odds of suffering from anxiety are 1.34 times greater than a woman who does not perceive the risk of involuntary job loss, holding all other variables constant. As for control variables, results indicate that older females, working women with tertiary education, the self-employed and women working in the public sector, those with a poor work-life fit, those less satisfied about their job, and female workers who are the main earner in the household are more likely to report anxiety.

We run the same model on the male subsample (Table 3) and found that $11.2 \%$ of the variance in the dependent variable may be attributed to country-level variables. The findings suggest that if a worker indicates his fear of losing his job in the future, the odds of suffering from anxiety are 1,43 higher than a man who does not report the worry of future job loss, holding all other variables constant. Thus, Hypothesis 1 is confirmed. We tested possible gender-differences in the association between anxiety and perceived job insecurity by adding an interaction term in the equation: parameter estimates for gender were not significant. Thus, Hypothesis 2 is confirmed, too: there are no gender differences in the association between perceived job insecurity and anxiety.

As a further step in the model building process, both intercepts and slopes were allowed to vary across countries (Model 3). Based on the parameter and standard error estimates, we may conclude that the relationship between anxiety and perceived job insecurity, which is positive and statistically significant, varies across countries for both male and female workers; however, the variance in slopes across countries is small. The covariance between intercepts and slopes is negative but not statistically significant. Post-estimation statistics, namely likelihood-ratio test 


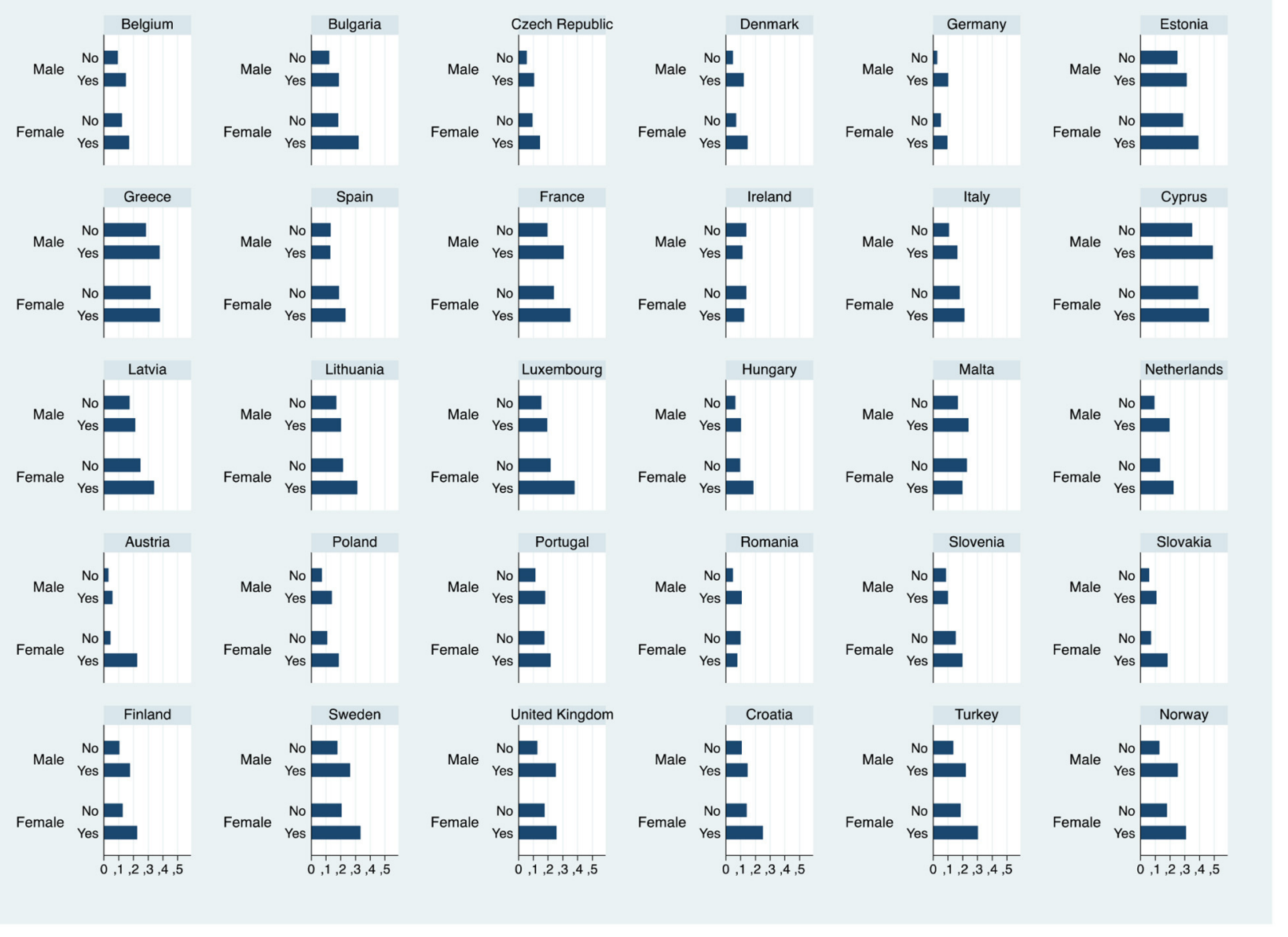

FIGURE 1 | Proportion of workers who report anxiety, by job insecurity perception, gender, and country.

and Akaike's information criteria, indicate that Model 3 fits the data better than Model 2.

Figure 2 displays the extent to which the slope of the relationship under investigation changes across countries, relative to the general trend, in the female subsample. In most countries, the probability of female workers suffering from anxiety as perceived job insecurity increases does not differ significantly from the overall pattern. Moreover, most confidence intervals of parameter estimate overlap. That means that the association between anxiety and job insecurity perception seems fairly stable across most European countries. However, it is worth noticing that the observed association is higher in Austria and lower in Cyprus, Malta and Italy, compared to the European average. Concerning men (Figure 3), the effect of perceived job insecurity on anxiety is smaller and significantly different from the European average in Germany.

\section{DISCUSSION AND CONCLUSION}

The findings of this study, which prove a significant association between perceived job insecurity and anxiety in the European labor force, confirm research in the field documenting that women seem to react negatively, and in the same way as men do, to adverse work and employment conditions (Pelfrene et al., 2003; László et al., 2010; Buffel et al., 2015; Reichert and Tauchmann, 2017; Menéndez-Espina et al., 2019). The magnitude of the association between job security and anxiety may be regarded as moderate and such result is also consistent with previous evidence (László et al., 2010; Buffel et al., 2015). However, the meta-analysis conducted by Sverke et al. (2002) indicated that the fear of involuntary job loss is more strongly associated to mental health as compared to physical health; accordingly, public health consequences of job insecurity need to be seriously considered, given that the current labor market transformations (OECD, 2014) are likely to result in a higher prevalence of workers, both males and females, feeling threatened by threat of job loss.

As a second step, we employed multilevel modeling to investigate whether job insecurity could be a more pronounced stressor in specific European countries. In this regard, as in previous studies as (Erlinghagen, 2008; László et al., 2010; Balz, 2017) we found evidence of cross-national differences in the 


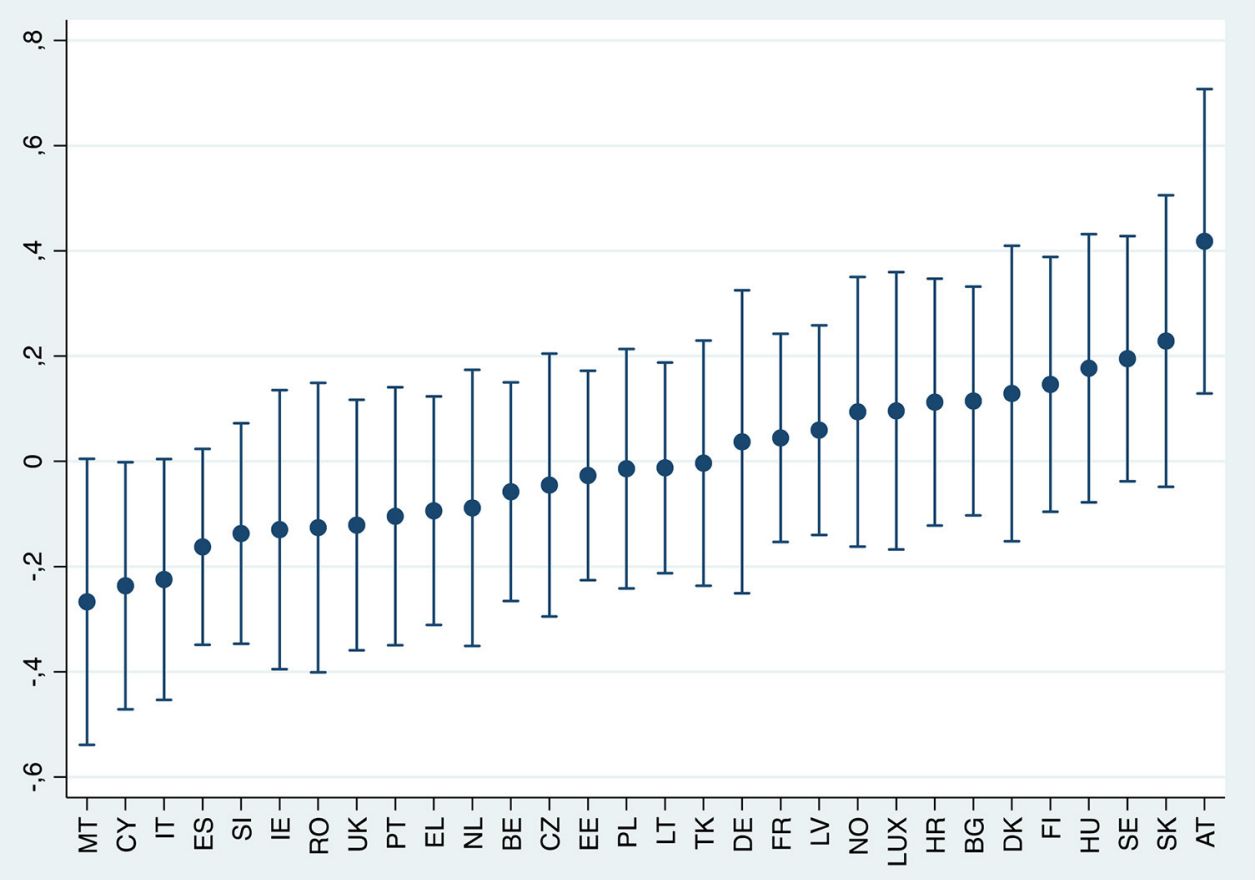

FIGURE 2 | Best linear unbiased predictions of the random effects for perceived job insecurity, by country (female subsample).

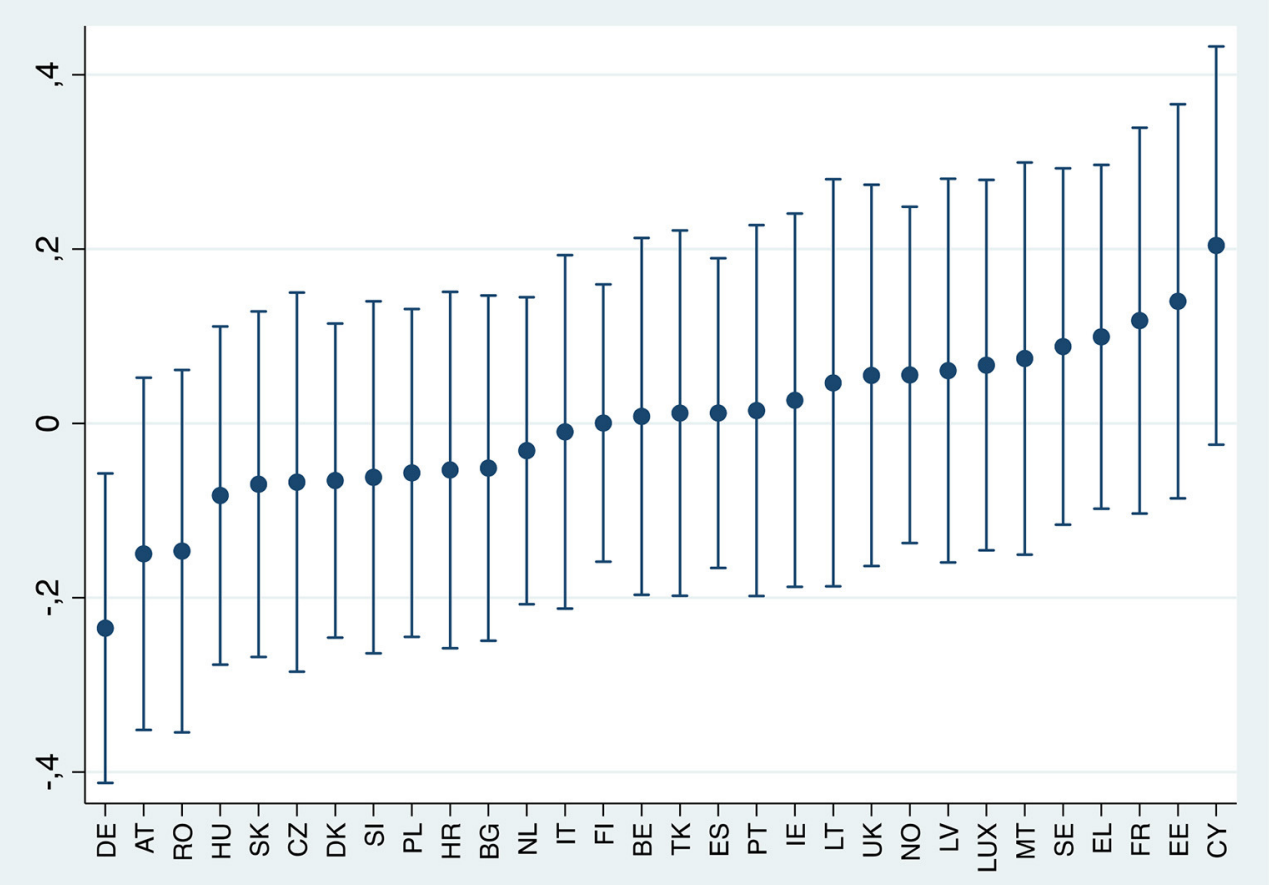

FIGURE 3 | Best linear unbiased predictions of the random effects for perceived job insecurity, by country (male subsample). 
TABLE 2 | Results of mixed-effects logistic regression model (female subsample).

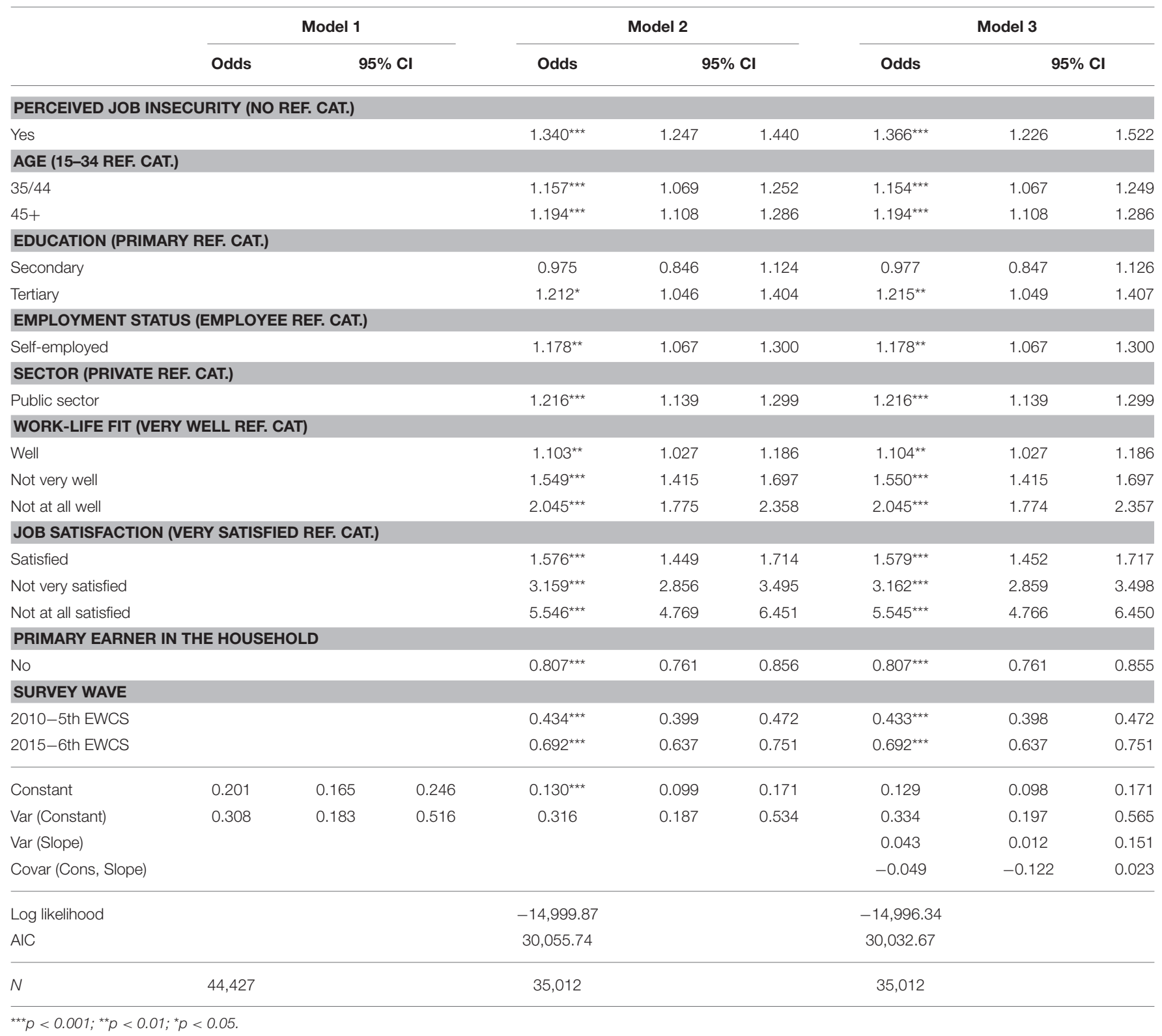

relationship between anxiety and perceived threats of job loss. However, analyses also indicate that the variation in effect sizes across countries is relatively small. Little heterogeneity in the association between job insecurity and anxiety across European countries for female workers, i.e., the main focus of this special issue, may be explained by the increasing prevalence of similar gender norms and roles and by recent trends toward greater gender egalitarianism (Kachi et al., 2018). On the other hand, some authors suggest that the risk of poor health resulting from insecure jobs may exist also in countries with good welfare regimes (Erlinghagen, 2008; László et al., 2010). We may also argue that the effects of job insecurity on mental health among working women may be triggered more by observed (and unobserved) individual and firm characteristics than contextual factors on the macro level. In this regard, our study indicates that much of the variance is attributable to variance in the intercepts (i.e., in the average levels of female workers reporting anxiety) and to micro or meso-level variables. These speculations are not mutually exclusive. In contrast to the "role theory" (Wang et al., 2008), more gender egalitarianism (i.e., beliefs about appropriate roles for men/women) seems to emerge in Europe, following major changes in women's educational attainment and employment patterns (OECD, 2019). However, as Mühlau (2011) maintains, gender-egalitarian norms do not necessarily lead to better working conditions for women. Women may need to work harder to compensate pay disadvantage, particularly in 
TABLE 3 | Results of mixed-effects logistic regression model (male subsample).

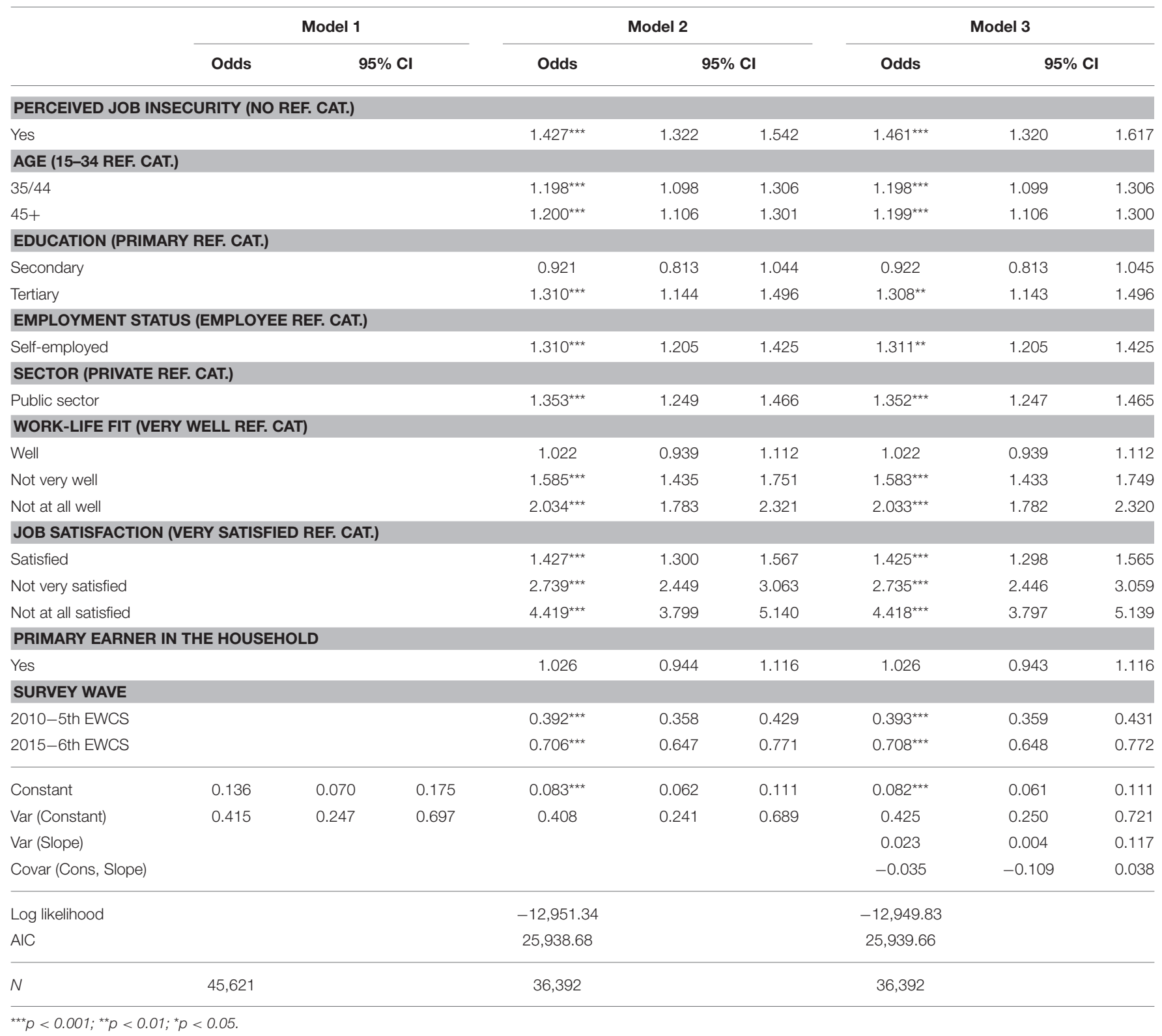

insecure and temporary jobs (Kachi et al., 2018), or to try and balance work and family responsibilities, which is still quite hard also within dual-earner and dual-career households (OECD, 2017).

As already anticipated, the findings of this study have practical implications for policymakers, as "policies that influence the length, continuity and nature of employment are likely to impact health" (Avendano and Berkman, 2014). Firstly, employment protection policies may incentive workers and employers' investments in training and safety exploiting changes in legislation to reduce insecurity from contractual arrangements. Because of the reduction of labor market rigidities, employers currently have few incentives to invest in temporary or casual workers' human capital than workers in permanent contracts. Most importantly, the nature of work should be taken into account in the field of labor policy that, in the current workfare priority, aims exclusively at a quick placement into a job (Munoz de Bustillo et al., 2011). This is particularly relevant in the context of aging workforce, where active aging policies stress the need to adapt professional conditions to older workers (Greenan et al., 2013). From a gender perspective, the predominant role that women still have as primary caregivers has strong consequences in female career and professional choices or opportunities. Tackling gender inequalities should be a key policy priority in order to provide all workers with adequate opportunities for selfvalidation, self-development and meeting their material needs 
over the life course (Grimshaw et al., 2017). In this regard, family support policies (e.g., maternity leave policies, better work-life balance arrangements, policies aimed at closing the gender wage gap) may lead to better women's health in the long run by improving their careers and earning trajectories (Avendano and Berkman, 2014; OECD, 2017).

Even if this study certainly adds to our understanding of health-related consequences of perceived job insecurity, the findings are subject to certain limitations, which need to be acknowledged. A source of weakness, which is common to most previous research, is the measurement of the dependent variable, which is a self-reported evaluation of mental health. Coherently, further research should employ objective measures and/or more comprehensive or multidimensional indicators of self-perceived of health (see e.g., Buffel et al., 2015; Moscone et al., 2016). This study was also limited by the absence of longitudinal information, which could enable the measurement of within-sample change over time and the assessment of cause-and-effect relationships, based on established sequences of events. Unfortunately, the European Working Conditions Survey, which has been used in this article, does not allow disentangling negative health risks from changes in job security and accumulated economic insecurity experiences, to whom women are particularly vulnerable (Avendano and Berkman, 2014; Watson and Osberg, 2017). Coherently, a natural progression of this study could be to address the same research question by using cross-country panel data, which could provide more definitive further evidence. De Witte et al. (2016) have systematically reviewed longitudinal studies on the association between job insecurity and health and well-being, but they have limited their examination to specific contexts. Further research in a life course perspective, which is being a predominant framework of sociologic and epidemiological research (Siegrist and Wahrendorf, 2016), can likely be extended by exploiting retrospective or longitudinal

\section{REFERENCES}

Avendano, M., and Berkman, L. (2014). "Labor markets, employment policies, and health," in Social Epidemiology, eds L. F. Berkman, I. Kawachi, and M. Glymour (Oxford: Oxford University Press), 182-233. doi: $10.1093 / \mathrm{med} / 9780195377903.003 .0006$

Balz, A. (2017). Cross-national variations in the security gap: perceived job insecurity among temporary and permanent employees and employment protection legislation. Eur. Sociol. Rev. 33, 675-692. doi: 10.1093/esr/jcx067

Berkman, L. F., Kawachi, I., and Theorell, T. (2014). "Working conditions and health," in Social Epidemiology, eds L. F. Berkman, I. Kawachi, and M. Glymour (Oxford: Oxford University Press), 153-181. doi: $10.1093 / \mathrm{med} / 9780195377903.003 .0005$

Bonoli, G. (2005). The politics of the new social policies: providing coverage against new social risks in mature welfare states. Policy Polit. 33, 431-449. doi: 10.1332/0305573054325765

Buffel, V., Dereuddre, R., and Bracke, P. (2015). Medicalization of the uncertainty? An empirical study of the relationships between unemployment or job insecurity, professional care seeking, and the consumption of antidepressants. Eur. Sociol. Rev. 31, 446-459. doi: 10.1093/esr/jcv004

Burgard, S. A., Brand, J. E., and House, J. S. (2009). Perceived job insecurity and worker health in the United States. Soc. Sci. Med. 69, 777-785. doi: 10.1016/j.socscimed.2009.06.029 data. The longitudinal design has potentially the strength to control for unobserved selection effects, which arise when workers at high risk of accepting less secure jobs may also have certain personality characteristics (Mel Bartley and Montgomery, 2005). Caution is, hence, required to interpret and generalize our results due to the cross-sectional design, which cannot include random measurement errors due to endogeneity from omitted variables and reverse causality as well. The interaction between work and health is likely bidirectional and we cannot distinguish between social causation (bad jobs are damaging to workers' health) and direct selection (workers with poor health are more likely to be less productive and be employed in insecure jobs (De Cuyper et al., 2008). Finally, there may be an issue of self-selection into employment as job insecurity is only observed among those who work. However, a selection effect is more substantial in countries where women are more likely than men to exit the labor force because of health and family reasons, resulting in a misrepresentation of economically insecure women in the analyses (Cottini, 2012; Watson and Osberg, 2017).

\section{DATA AVAILABILITY STATEMENT}

Publicly available datasets were analyzed in this study. Info on data availability can be found here: https://www.eurofound. europa.eu/surveys/about-eurofound-surveys/data-availability\# datasets.

\section{AUTHOR CONTRIBUTIONS}

$\mathrm{AB}$ has provided the theoretical support and drafted literature review. ER was responsible for data acquisition, data analysis, and presentation of the results. Both authors were responsible for discussing the results.
Caroli, E., and Godard, M. (2016). Does job insecurity deteriorate health? Health Econ. 25, 131-147. doi: 10.1002/hec.3122

Cheng, G., and Chan, D. (2008). Who suffers more from job insecurity? A meta-analytic review. Appl. Psychol. 57, 272-303. doi: 10.1111/j.1464-0597.2007.00312.x

Chung, H. (2018). Dualization and the access to occupational family-friendly working-time arrangements across Europe. Soc. Policy Admin. 52, 491-507. doi: $10.1111 /$ spol.12379

Cloutier, L., Bernard, P., and Tremblay, D. G. (2009). Job quality and gender inequality: key changes in Quebec over the last decade. Stud. Soc. Justice 3, 189-201. doi: 10.26522/ssj.v3i2.1015

Cottini, E. (2012). Is your job bad for your health? Explaining differences in health at work across gender. Int. J. Manpower 33, 301-321. doi: 10.1108/01437721211234174

Cottini, E., and Ghinetti, P. (2018). Employment insecurity and employees' health in Denmark. Health Econ. 27, 426-439. doi: 10.1002/hec.3580

De Cuyper, N., De Jong, J., De Witte, H., Isaksson, K., Rigotti, T., and Schalk, R. (2008). Literature review of theory and research on the psychological impact of temporary employment: towards a conceptual model. Int. J. Manage. Rev. 10, 25-51. doi: 10.1111/j.1468-2370.2007.00221.x

De Stefano, V. (2016). The rise of the "just-in-time workforce": on-demand work, crowdwork, and labor protection in the "gig economy." Compar. Labor Law Policy J. 37, 471-504. doi: 10.2139/ssrn.2682602 
De Witte, H., Pienaar, J., and De Cuyper, N. (2016). Review of 30 years of longitudinal studies on the association between job insecurity and health and well-being: is there causal evidence? Aust. Psychol. 51, 18-31. doi: 10.1111/ap.12176

Erlinghagen, M. (2008). Self-perceived job insecurity and social context: a multi-level analysis of 17 European countries. Eur. Sociol. Rev. 24, 183-197. doi: $10.1093 /$ esr/jcm042

Esping-Andersen, G. (1990). The Three Worlds of Welfare Capitalism. Cambridge: Polity Press.

Eurofound (2017a). Sixth European Working Conditions Survey-Overview report. Luxembourg: Publications Office of the European Union.

Eurofound (2017b). European Working Conditions Survey Integrated Data File, 1991-2015 [Data Collection]. 5th Edn. UK Data Service. SN: 7363.

Fagan, C., and Burchell, B. (2002). Gender, Jobs and Working Conditions in the European Union. Luxembourg: Eurofound.

Felstead, A., Gallie, D., and Green, F. (Eds.). (2015). Unequal Britain at Work. Oxford: Oxford University Press.

Ferrie, J. E., Shipley, M. J., Newman, K., Stansfeld, S. A., and Marmot, M. (2005). Self-reported job insecurity and health in the Whitehall II study: Potential explanations of the relationship. Soc. Sci. Med. 60, 1593-1602. doi: 10.1016/j.socscimed.2004.08.006

Green, F. (2011). Unpacking the misery multiplier: how employability modifies the impacts of unemployment and job insecurity on life satisfaction and mental health. J. Health Econ. 30, 265-276. doi: 10.1016/j.jhealeco.2010. 12.005

Green, F., and Mostafa, T. (2012). Trends in Job Quality in Europe: A Report Based on the Fifth European Working Conditions Survey. Dublin: Eurofound.

Greenan, N., Kalugina, E., and Walkowiak, E. (2013). Has the quality of working life improved in the EU-15 between 1995 and 2005? Ind. Corp. Change 23, 399-428. doi: 10.1093/icc/dtt012

Greenan, N., Seghir, M., Smiths, I., Szekér, L., Van Gyes, G., and Vercruyssen, A. (2017). Job Quality and Vulnerability-at-Work Indicators in Europe. Leuven: InGRID.

Griep, Y., Kinnunen, U., Nätti, J., De Cuyper, N., Mauno, S., Mäkikangas, A., et al. (2016). The effects of unemployment and perceived job insecurity: a comparison of their association with psychological and somatic complaints, self-rated health and life satisfaction. Int. Archiv. Occupat. Environ. Health 89, 147-162. doi: 10.1007/s00420-015-1059-5

Grimshaw, D., Fagan, C., Hebson, G., and Tavora, I. (Eds.). (2017). Making Work More Equal. A New Labor Market Segmentation Approach. Manchester: Manchester University Press.

Hall, P. A., and Soskice, D. (Eds.). (2001). Varieties of Capitalism, of Capitalism: The Institutional Foundations of Comparative Advantage. Oxford: Oxford University Press.

Hofstede, G. (1991). Cultures and Organizations: Software of the Mind. London; New York, NY: McGrawHill.

ILO (2016). Non-Standard Employment Around the World: Understanding Challenges, Shaping Prospects. Geneva: International Labor Office.

Janlert, U., and Hammarström, A. (2009). Which theory is best? Explanatory models of the relationship between unemployment and health. BMC Public Health 9:235. doi: 10.1186/1471-2458-9-235

Kachi, Y., Hashimoto, H., and Eguchi, H. (2018). Gender differences in the effects of job insecurity on psychological distress in Japanese workers: a population-based panel study. Int. Archiv. Occupat. Environ. Health 91, 991-999. doi: 10.1007/s00420-018-1338-Z

Kalil, A., Ziol-Guest, K. M., Hawkley, L. C., and Cacioppo, J. T. (2010). Job insecurity and change over time in health among older men and women. J. Gerontol. Soc. Sci. B 65, 81-90. doi: 10.1093/geronb/ gbp 100

Karasek, R. (1979). Job demands, job decision latitude, and mental strain: implications for job redesign. Admin. Sci. Q. 24, 285-308. doi: 10.2307/2392498

László, K. D., Pikhart, H., Kopp, M. S., Bobak, M., Pajak, A., Malyutina, S., et al. (2010). Job insecurity and health: a study of 16 European countries. Soc. Sci. Med. 70, 867-874. doi: 10.1016/j.socscimed.2009. 11.022

Mel Bartley, J. F., and Montgomery, S. M. (2005). "Health and labour market disadvantage: unemployment, non-employment, and job insecurity," in Social Determinants of Health, eds M. Marmot and R. Wilkinson (Oxford:
Oxford University Press), 78-96. doi: 10.1093/acprof:oso/9780198565895. 003.05

Menéndez, M., Benach, J., Muntaner, C., Amable, M., and O'Campo, P. (2007). Is precarious employment more damaging to women's health than men's? Soc. Sci. Med. 64, 776-781. doi: 10.1016/j.socscimed.2006. 10.035

Menéndez-Espina, S., Llosa, J. A., Agulló-Tomás, E., Rodríguez-Suárez, J., SáizVillar, R., and Lahseras-Díez, H. F. (2019). Job insecurity and mental health: the moderating role of coping strategies from a gender perspective. Front. Psychol. 10:286. doi: 10.3389/fpsyg.2019.00286

Milner, A., Aitken, Z., Kavanagh, A., La Montagne, A. D., and Petrie, D. (2016). Persistent and contemporaneous effects of job stressors on mental health: a study testing multiple analytic approaches across 13 waves of annually collected cohort data. Occupat. Environ. Med. 73, 787-793. doi: 10.1136/oemed-2016-103762

Moscone, F., Tosetti, E., and Vittadini, G. (2016). The impact of precarious employment on mental health: the case of Italy. Soc. Sci. Med. 158, 86-95. doi: 10.1016/j.socscimed.2016.03.008

Mühlau, P. (2011). Gender inequality and job quality in Europe. Manage. Rev. 22, 114-131. doi: 10.5771/0935-9915-2011-2-114

Munoz de Bustillo, R., Fernandez-Macias, E., Anton, J. I., and Esteve, F. (2011). Measuring More than Money. The Social Economics of Job Quality. Northampton, MA: Edward Elgar.

O'Campo, P., Eaton, W. W., and Muntaner, C. (2004). Labor market experience, work organization, gender inequalities and health status: results from a prospective analysis of US employed women. Soc. Sci. Med. 58, 585-594. doi: 10.1016/S0277-9536(03)00230-2

OECD (2012). Sick on the Job? Myths and Realities About Mental Health and Work, Mental Health and Work. Paris: OECD Publishing.

OECD (2014). Non-regular Employment, Job Security and the Labor Market Divide. OECD Employment Outlook 2014. Paris: OECD Publishing.

OECD (2017). The Pursuit of Gender Equality: An Uphill Battle. Paris: OECD Publishing.

OECD (2019). OECD Employment Outlook 2019: The Future of Work. Paris: OECD Publishing.

Olsen, K. M., Kalleberg, A. L., and Nesheim, T. (2010). Perceived job quality in the United States, Great Britain, Norway and West Germany, 1989-2005. Eur. J. Ind. Relat. 16, 221-240. doi: 10.1177/09596801103 75133

Pelfrene, E., Vlerick, P., Moreau, M., Mak, R. P., Kornitzer, M., and Backer, G. (2003). Perceptions of job insecurity and the impact of world market competition as health risks: results from Belstress. J. Occupat. Organ. Psychol. 76, 411-425. doi: 10.1348/096317903322 591569

Reichert, A. R., and Tauchmann, H. (2017). Workforce reduction, subjective job insecurity, and mental health. J. Econ. Behav. Organ. 133, 187-212. doi: 10.1016/j.jebo.2016.10.018

Sengenberger, W. (2011). Beyond the Measurement of Unemployment and Underemployment: The Case for Extending and Amending Labor Market Statistics. Geneva: International Labor Office.

Siegrist, J., and Wahrendorf, M. (Eds.). (2016). Work Stress and Health in a Globalized Economy: The Model of Effort-Reward Imbalance. Cham: Springer International Publishing.

Simmons, L. A., and Swanberg, J. E. (2008). Psychosocial work environment and depressive symptoms among US workers: comparing working poor and working non-poor. Soc. Psychiatry Psychiatr. Epidemiol. 44, 628-635. doi: 10.1007/s00127-008-0479-x

Simões, N., Crespo, N., and Pinto, J. C. (2015). Determinants of job quality-evidence for European country groups. Acta Oecon. 65, 299-323. doi: 10.1556/032.65.2015.2.6

Stier, H., and Yaish, M. (2014). Occupational segregation and gender inequality in job quality: a multi-level approach. Work Employ. Soc. 25, 225-246. doi: 10.1177/09500170135 10758

Sverke, M., Hellgren, J., and Naswall, K. (2002). No security: a meta-analysis and review of job insecurity and its consequences. J. Occupat. Health Psychol. 7, 242-264. doi: 10.1037/1076-8998. 7.3.242 
Wang, J. L., Lesage, A., Schmitz, N., and Drapeau, A. (2008). The relationship between work stress and mental disorders in men and women: findings from a population-based study. J. Epidemiol. Commun. Health 62, 42-47. doi: $10.1136 /$ jech.2006.050591

Watson, B., and Osberg, L. (2017). Healing and/or breaking? The mental health implications of repeated economic insecurity. Soc. Sci. Med. 188, 119-127. doi: 10.1016/j.socscimed.2017.06.042

Wood, A., and Burchell, B. (2018). "Unemployment and well-being," in Cambridge Handbook of Psychology and Economic Behaviour, ed A. Lewis (Cambridge: Cambridge University Press), 234-259. doi: 10.1017/9781316676349.008
Conflict of Interest: The authors declare that the research was conducted in the absence of any commercial or financial relationships that could be construed as a potential conflict of interest.

Copyright (C) 2020 Bracci and Riva. This is an open-access article distributed under the terms of the Creative Commons Attribution License (CC BY). The use, distribution or reproduction in other forums is permitted, provided the original author(s) and the copyright owner(s) are credited and that the original publication in this journal is cited, in accordance with accepted academic practice. No use, distribution or reproduction is permitted which does not comply with these terms. 